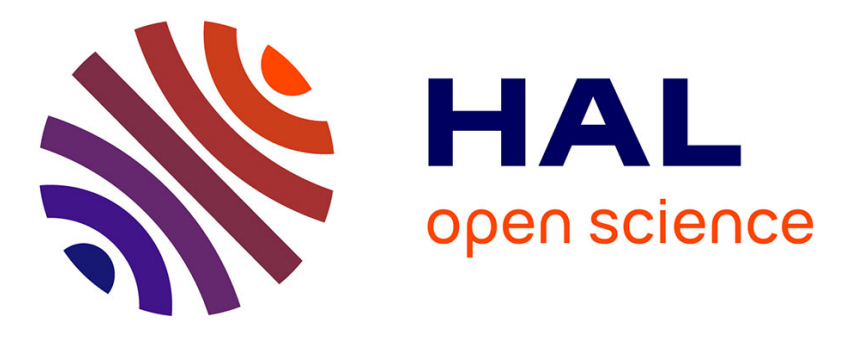

\title{
Ready for the future? A survey on open access with scientists from the French National Research Center (CNRS)
}

\author{
Joachim Schöpfel, Coline Ferrant, Francis Andre, Renaud Fabre
}

\section{To cite this version:}

Joachim Schöpfel, Coline Ferrant, Francis Andre, Renaud Fabre. Ready for the future? A survey on open access with scientists from the French National Research Center (CNRS). Interlending and Document Supply, 2016, 44 (4), pp.141-149. 10.1108/ILDS-06-2016-0023 . hal-01399422

\section{HAL Id: hal-01399422 \\ https://hal.science/hal-01399422}

Submitted on 11 Apr 2017

HAL is a multi-disciplinary open access archive for the deposit and dissemination of scientific research documents, whether they are published or not. The documents may come from teaching and research institutions in France or abroad, or from public or private research centers.
L'archive ouverte pluridisciplinaire HAL, est destinée au dépôt et à la diffusion de documents scientifiques de niveau recherche, publiés ou non, émanant des établissements d'enseignement et de recherche français ou étrangers, des laboratoires publics ou privés.

\section{(c)(1)}

Distributed under a Creative Commons Attribution| 4.0 International License 


\title{
Ready for the Future? A Survey on Open Access with Scientists from the French National Research Center (CNRS)
}

\author{
Joachim Schöpfel \\ GERiiCO laboratory, University of Lille \\ Villeneuve d'Ascq, France

\section{Coline Ferrant} \\ Observatoire Sociologique du Changement, Sciences Po / CNRS \\ Paris, France \\ Northwestern University, Evanston, IL, US \\ Alimentation et Sciences Sociales, INRA \\ Ivry-sur-Seine, France \\ Francis André \\ Scientific and Technical Information Department, CNRS \\ Paris, France

\section{Renaud Fabre} \\ Scientific and Technical Information Department, CNRS \\ Paris, France \\ Corresponding author: Joachim Schöpfel \\ Corresponding Author's Email: joachim.schopfel@univ-lille3.fr
}

\begin{abstract}
:
Purpose: The paper presents empirical evidence on the opinion and behaviour of French scientists (senior management level) regarding open access to scientific and technical information.

Approach: The results are part of a nationwide survey on scientific information and documentation with 432 directors of French public research laboratories conducted by the French Research Center CNRS in 2014.

Findings: 1. The CNRS senior research managers (laboratory directors) globally share the positive opinion towards open access revealed by other studies with researchers from the UK, Germany, the United States and other countries. However, they are more supportive of open repositories (green road) than of OA journal publishing (gold). 2. The response patterns reveal a gap between generally positive opinions about open access and less supportive behaviours, principally publishing articles with APCs. 3. A small group of senior research managers does not seem to be interested in green or gold open access and reluctant to self-archiving and OA publishing. 4. Similar to other studies, the French survey confirms disciplinary differences, i.e. a stronger support for self-archiving of records and documents in HAL by scientists from Mathematics, Physics and Informatics than from Biology, Earth Sciences and Chemistry; and more experience and positive feelings with open access publishing and payment of APCs in Biology than in Mathematics or in Social Sciences and Humanities. Disciplinary differences
\end{abstract}


and specific French factors are discussed, in particular in the context of the new European policy in favour of Open Science.

Originality: For the first time, a nationwide survey was conducted with the senior research management level from all scientific disciplines. The response rate was high $(>30 \%)$, and the results provide good insight into the real awareness, support and uptake of open access by senior research managers who provide both models (examples for good practice) and opinion leadership.

\section{Keywords: Open access, open repositories, open science, self-archiving, OA publishing, research management.}

\section{Article Classification: Research paper}

\section{Introduction}

"Winds of change are blowing throughout scholarly communications - it has culminated in a so-called 'perfect storm' (which) arises from the confluence of several largely unrelated trends" (Brown 2016, p.22). One of these trends is openness, a "broad social movement involving significant cultural change" (ibid, p.340).

\section{Open Science}

Openness to science, or Open Science, is at the top of the research agenda of the European Union. In Horizon 2020, the European Research and Innovation Framework Programme running from 2014 to 2020 open access to publications has become mandatory. Also, the European Commission is commencing a policy process on Open Science, considered as "the transformation, opening up and democratisation of science, research and innovation, with the objective of making science more efficient, transparent and interdisciplinary, of changing the interaction between science and society, and of enabling broader societal impact and innovation" (Ramjoué 2015, p.169). Open access is, together with open research data, a key component for the emergence of a new ecosystem of standards and services of scientific information.

More recently, the European commitment to Open Science was confirmed and reinforced by the Amsterdam Call for Action on Open Science ${ }^{1}$ which formulates a "multi-actor approach (...) to reach two important pan-European goals for 2020 ", i.e. full open access for all scientific publications and a fundamentally new approach towards optimal reuse of research data. The Amsterdam Call for Action describes twelve concrete action items to be taken by the European Commission, the EU Member States and the stakeholders, such as research funders, national authorities, publishers and private partners. Research performing organisations and the research communities play a central role to agree on open access principles, promote mutual understanding, put in place new policies, set new standards and coordinate activities in favour of open access and open data. Scientists and their organisations and institutions are not the only stakeholders. But without their support and involvement, the ambitious goals will not be reached, neither in 2020 nor later on.

\footnotetext{
${ }^{1}$ Source: The Netherlands EU Presidency 2016, April 2016 http://english.eu2016.nl/documents/reports/2016/04/04/amsterdam-call-for-action-on-open-science
} 


\section{The French National Center for Scientific Research (CNRS)}

In terms of scientific output (articles, citations) and innovation (patents), France is one of the leading Member States of the European Union, together with the United Kingdom and Germany. In 2014, French scientists published nearly 105,000 articles ${ }^{2}$, and France spent $2.3 \%$ of its GDP on research and innovation, a sector with about 366,000 researchers ${ }^{3}$. The National Center for Scientific Research, or $\mathrm{CNRS}^{4}$, is a public organization under the responsibility of the French Ministry of Education and Research. As the largest fundamental research organization in Europe, the CNRS carries out research in all fields of knowledge, through its ten institutes (life sciences, chemistry, physics etc.) and 32,500 staff members in more than 1,000 research units (laboratories).

One of the first signatories of the Berlin Declaration on Open Access, the CNRS is deeply committed to open access, in particular through funding of the national HAL repository with 388,771 documents $^{5}$ and of the OpenEdition platform with 431 journals and 2,719 monographs in open access ${ }^{6}$. Also, the CNRS supports national, European and international initiatives and projects in favour of open access and Open Science, with a clear preference for self-archiving of publications and data in open repositories (green road).

One part of the CNRS scientific output (annual average 35,500 publications) is freely available through HAL, arXiv and other open repositories, and in commercial or non-profit open access or hybrid journals. The exact percentage is hard to estimate, but it is probably at a comparable level with other European research organisations, i.e. about 20 to $30 \%$. With the European Council defining a $100 \%$ open access goal for 2020, it still has a long way to go. Is the CNRS willing to meet the challenge? Are the CNRS researchers ready to move forward?

\section{Recent surveys}

In recent years, a couple of surveys have assessed the researchers' understanding and awareness of open access and their attitudes and motivation towards the green and gold road, as key factors of the success of open access. More than ten years ago, in an international study with 1,296 authors, $49 \%$ of the respondent population had self-archived at least one article during the last three years but a substantial proportion of authors was still unaware of the possibility of providing open access to their work by self-archiving (Swan \& Brown 2005). These results were corroborated by a 2008 survey with UK researchers that revealed some "suspicion of open access publications" and ignorance about open access and the role of institutional repositories, and suggested that a degree of culture change may be needed (Creaser 2010).

On the other side, based on a sample of over 3,000 European scholars, Fry et al. (2010) reported not only a good understanding and appreciation of the ethos of open access in general but also clear differences between disciplines. This was confirmed by Eger et al. (2013) in a study with 2,151 researchers in Germany that revealed significant differences between the scientific disciplines with respect to researchers' awareness of and experience with OA journals and self-archiving. "The perceived relevance and reputation of OA within one's discipline may explain why researchers from particular disciplines (do not) publish in OA journals. Besides, several determinants like age, profession or the discipline specific reward system play a role. In general, discipline-specific incentives matter" (p.4).

In 2014, the European University Association conducted a survey on the development and degree of implementation of institutional policies on open access with 106 universities (EUA

\footnotetext{
${ }^{2}$ Source: SCImago Lab, http://www.scimagojr.com/

${ }^{3}$ Source: OECD https://data.oecd.org

${ }^{4}$ Source: CNRS http://www.cnrs.fr/

${ }^{5}$ Source: HAL https://hal.archives-ouvertes.fr/ (13 May 2016)

${ }^{6}$ Source: OpenEdition http://www.openedition.org/ (7 May2016)
} 
2015). About $60 \%$ reported that the main element in their institutional policy was encouraging researchers to deposit their publications in an open repository. Concerns over copyright infringement were identified as the most frequent barrier regarding self-archiving, and the researchers' awareness of the journal publishers' policies on open access was generally considered as low.

Morris \& Thorn (2009) surveyed individual members of 35 UK learned societies on their attitudes to open access. Most of their 1,368 respondents were aware of OA and in favour of increased access through OA journals, even if their real knowledge and practice were lagging behind. The access and convenience of self-archiving repositories were seen as positive but there was "less support in principle for self-archiving than for OA journals $-36.37 \%$ of respondents are in favour, compared with $74.11 \%$ for OA journals" (p.237). However, only one quarter of the authors claimed to self-archive at least some of their articles, and the major concerns expressed were about workload, "lack of quality control, and proliferation of multiple versions of articles" (ibid).

Further studies of author perceptions on open access reveal general features as well as domain specific aspects (see overviews by Björk et al. 2010 and Nariani \& Fernandez 2012). Among the general features are a globally favourable stance towards open access, yet little awareness of OA in general and journal publishing in particular, especially outside of physics, and a general reluctance to pay article processing charges (APCs), mainly in the absence of institutional support. The same response patterns were found by the large SOAP survey with 38,358 authors $-89 \%$ answered that OA journal publishing was beneficial to their field but only $52 \%$ had already published in OA; funding and journal quality were identified as the main barriers (Dallmeier-Tiessen et al. 2011). In a smaller survey with 481 researchers, 85\% liked the idea of open access publishing; "almost two-thirds $(66 \%)$ of the respondents have used Open Access publication media for accessing research results at least once in their academic career. But only about one quarter $(28 \%)$ of the researchers have used them for actual publishing the results of their work" (Mann et al. 2009, p.136).

In the Mann et al. survey, "despite their positive general attitude, the majority of the survey participants $(61 \%)$ fear that Open Access publishing might jeopardize their chances of promotion and tenure. At the same time, 63\% worry about Open Access publishing damaging their chances for research funds" (ibid.). Still, reputation and prestige are more important factors for the choice of a journal than openness or business models - in other words, career prevails when it comes to deciding where and how to disseminate research results.

Reviewing recent surveys on authors' attitudes towards open access and journal publishing, the 2015 STM Report puts it this way: "That there are benefits of open access seem generally accepted: only $11 \%$ said OA had no fundamental benefits" (Ware \& Mabe 2015, p.71); also, "authors believe journals will remain as the principal publication outlet, demarcating quality research, but a significant proportion of research papers will be published only in subject or institutional repositories that will coexist with journals" (p.72). The "main factors affecting author choice of journal (remain) the journal's quality, its relevance, and speed of publication (in that order)" (p.71).

\section{Questions}

All survey results converge towards the fact that the researchers have generally accepted the idea of open access and that they consider it as globally beneficial for their field, even if their information and publishing behaviour may be somewhat delayed. In Europe, 461 research organisations and funders have adopted open access mandates and policies that require or request their researchers to provide open access to their peer-reviewed research article output by depositing it in an open access repository ${ }^{7}$; many have signed national or

\footnotetext{
${ }^{7}$ Source: ROARMAP http://roarmap.eprints.org/ (14 May 2016)
} 
international statements on open access, such as the Berlin Declaration. Both, individual awareness and uptake and institutional, political commitment are crucial for the further progress of open access.

Senior researchers, especially research managers and directors of research centres, are key stakeholders in this process in two ways:

- They are appointed by their peers, coordinate the research activities and represent their colleagues in the executive and advisory bodies; as such, they act as a kind of transmission belt of the researchers' opinions and demands, including reporting (bottom-up).

- At the same time, they stand for the research organisation and are the guardians of the application of institutional decisions and rules within the local laboratory, including supervision, follow-up and control (top-down).

This intermediary or middle function may not always be an easy situation, as a latent source of conflict, but it makes them particularly interesting and influential as opinion leaders and even as potential models for good practice. For this reason, instead of a new assessment of scientists' attitudes and behaviours towards open access, the CNRS conducted an exploratory survey on Scientific and Technological Information (STI) specifically at the senior management level, i.e. the directors of the CNRS research units (laboratories). One part of this survey was about open access. Our paper reports the survey results on open access, in particular to obtain answers to four questions:

1. Do the CNRS senior research managers (laboratory directors) share the positive opinion towards open access revealed by recent studies with researchers from the UK, Germany, the United States and other countries? Are they supportive of open repositories and OA journal publishing?

2. Does their information behaviour, i.e. use and production of open access publications, meet the challenge of open access or does it lag behind their opinions?

3. Like in other studies, will this survey identify a group of unaware or even reluctant senior research managers not interested in open access?

4. And finally, what can be said about differences between scientific disciplines?

\section{Methodology}

The survey was conducted between July and September 2014 by the CNRS Scientific and Technical Information Department (DIST) ${ }^{8}$. A questionnaire with 91 items was sent to the directors of the 1,250 CNRS research laboratories representing all areas of fundamental science. The survey was a component of an internal audit on the CNRS STI policy and service development. Part of the demand analysis, the items' objective was to assess attitudes and needs expressed by research managers regarding four particular functions of scientific information: access to scientific information, publishing of research results, analysis of scientific information (scientometrics), and other research support services, including ethics and legal advice.

432 laboratory directors completed the questionnaire (35\%). The respondents are a representative sample of the CNRS research institutes (social sciences and humanities, life sciences, chemistry, engineering and systems sciences etc.) and of the geographical distribution (Paris, regions).

Fifteen items dealt with different aspects of open access to scientific information - access as well as dissemination, green road as well as gold road, legal advice as well as technical assistance, and global questions on open access alternated with specific items related to the French open access infrastructure, i.e. the HAL repository (see appendix 1).

\footnotetext{
${ }^{8}$ Direction de l'Information Scientifique et Technique http://www.cnrs.fr/dist/
} 
The raw results were published in March $2015^{9}$. This paper reports a re-analysis of the survey data in particular:

- to explore experiences with green and gold open access,

- to assess the general attitudes of French research managers to open access,

- to evaluate specific needs and demands, and

- to analyse the differences between scientific disciplines.

The findings will be discussed from three different points of view: Are French research managers different from those of other countries when it comes to open access? Do they form a relatively homogeneous group or can we distinguish different "clusters"? And in particular, is there a clearly reluctant or even hostile group of researchers opposed to open access as an alternative to traditional publishing? The discussion will also mention the progress made toward open access in France since 2014.

\section{Findings}

As indicated above, 432 research unit directors (senior managers) completed the questionnaire. No question was mandatory. The response rates per question are relatively high and range from 0.73 to 0.97 (median 0.91).

Seven questions assess past experiences with open access, e.g. deposit of records and documents in HAL or the payment of APCs. Three questions evaluate the respondents' global attitudes towards open access, in particular towards resource sharing, European networking and APCs. Finally, five questions explore specific demands and needs, such as the promotion and future development of HAL, including a mandatory policy (for more details see Appendix 1 and footnote 9). For each question, the responses can be analysed as "positive" (in favour of OA, interested, experience with HAL or OA publishing) or "negative" (opposed to OA, no experience, not interested, no priority). In other terms, "positive" means "experience/practice with OA", "positive attitude" or "interested in strengthening OA", according to each question.

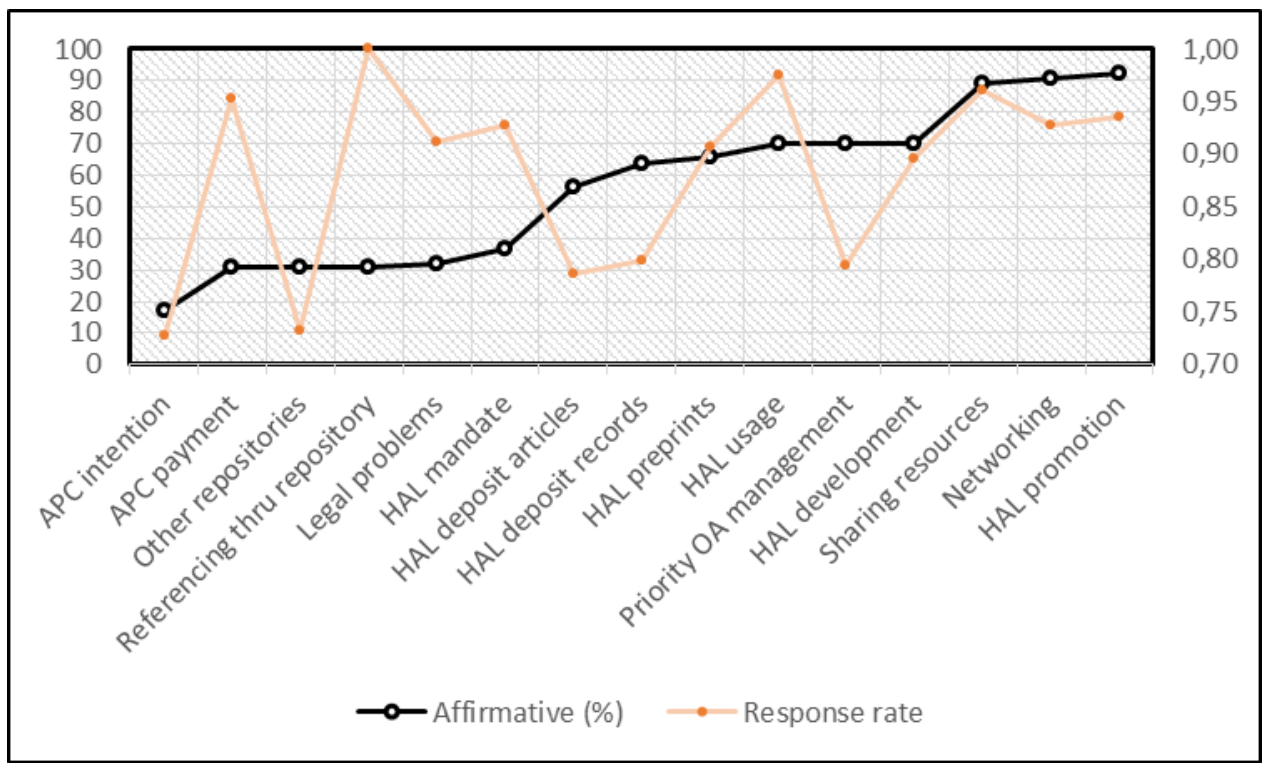

Figure 1: OA affirmative responses (with response rates)

Figure 1 shows the "positive" response rate for all fifteen questions. Three groups can be clearly distinguished: three questions with a high positive response rate $(0.90)$ which express

\footnotetext{
${ }^{9}$ http://www.cnrs.fr/dist/z-outils/documents/Enquête\%20DU\%20-\%20DIST\%20mars\%202015.pdf
} 
a high consensus in favour of open access; six questions with a dominant positive response rate (0.50-0.70), reflecting a majority opinion in favour of open access; and six other questions with low positive response rates $(<0.40)$ where the positive experiences and attitudes are shared by a minority of respondents.

\section{Consensus}

The survey reveals a large consensus on three questions, with about $90 \%$ affirmative responses and a high response rate of 0.95 . Nine out of ten respondents are willing to share their scientific results with scientists from other laboratories (\#25) and are in favour of the sharing of open access deposits through an European or international network (\#37), and they think that the national open repository HAL should be better known and promoted (\#30). These responses reflect a general scientific attitude (community, internationality) together with a large global support in favour of the HAL repository.

\section{Majority opinion and practice}

A majority of respondents - 50-70\% - declares actual usage of the HAL repository (\#26), including deposit of metadata (records, \#27) and documents (full text, \#28) and demands further development of the HAL services (\#31).

Between $65 \%$ and $70 \%$ of the respondents also demand that HAL should improve on the distinction between preprints (unpublished) and other items, i.e. published articles (\#32), and should put open access management on the top of the wish list for new service developments (\#84).

\section{Minority opinion and practice}

Other questions about open access did not receive a majority of affirmative or positive answers. Here, four different aspects can be distinguished:

Mandate: Nearly $40 \%$ of the respondents are in favour of an institutional mandate, in other words, they ask that the deposit in HAL should become mandatory (\#36). This is not a small group but nevertheless, it does not express a majority opinion.

APCs: Only 30\% declare having paid APCs so far for an open access article (\#38), and less than $20 \%$ of the others say that they intend to do so in the future (\#39). Even when both groups are taken together, they don't reach a majority and remain below $50 \%$.

Usage of other repositories: HAL is the dominant French open repository in the heart of the academic ICT infrastructure. Only 30\% of the respondents say that they (also) use other repositories than HAL for their publications (\#29), which confirms the central role of HAL for the CNRS laboratories.

Other issues: About $30 \%$ have already had legal problems with the deposit of copyrighted material in an open repository (\#88), and as many say that they would use an open repository for the referencing of their scientific output (\#41), for scientometrics, evaluation and so on.

\section{Disciplinary differences}

As mentioned above, the 432 senior managers come from all ten research institutes. Each institute representing a specific research field or discipline (see Appendix 2), the results can also be analysed against the different disciplines. Our observations of differences between disciplines are based on Pearson's chi-squared $\left(\mathrm{X}^{2}\right)$ tests of the response patterns per institute. 


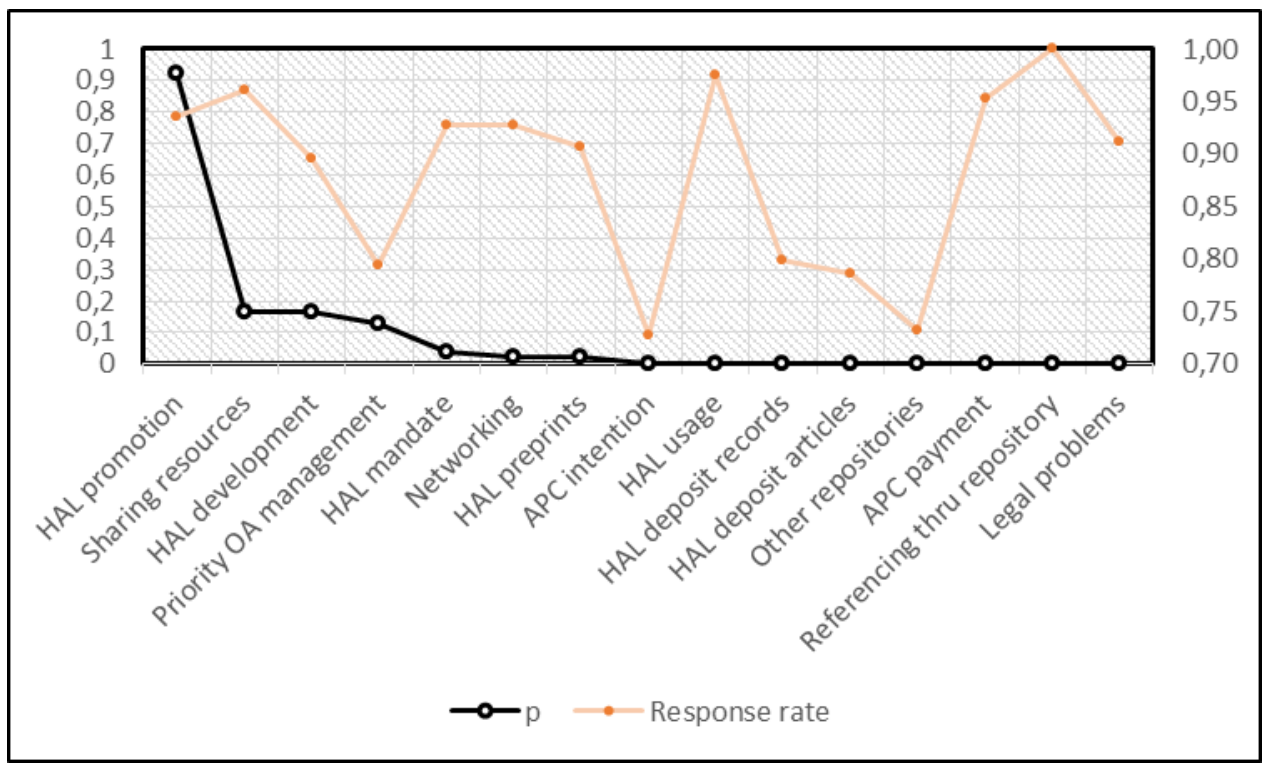

Figure 2: Disciplinary differences in questions $\left(\mathrm{X}^{2}\right.$ test, $\mathrm{P}$-values $)$

The fifteen questions were ranked according to their level of confidence in the $\mathrm{X}^{2}$ test (figure 2). Again, three groups of questions can be distinguished. Four questions have a low $\mathrm{X}^{2}$ with a confidence level $\mathrm{p}$ between 0.131 and 0.925 . For these items, there are few or no differences between the institutes - all are convinced of the need for open access management (\#84) and for more promotion and further development of the CNRS open access services and tools (\#30), in particular HAL (\#31), and all are willing to share their digital resources with other scientists (\#25).

For three other questions, the confidence levels p range from 0.022 to 0.039 , i.e. there are significant differences between the institutes at the 0.05 level. Three items are related to green open access in general (\#37 European networking) and HAL in particular (\#32 distinction of preprints and \#36 mandate).

Together, these seven questions have in common the fact that they all assess either opinions (attitudes) or needs (demands, interest). Obviously, the disciplinary differences have more to do with experiences, behaviours and practice of open access. Except for one item (\#39 intention to pay APCs), all questions statistically significant at the 0.001 level are related to past experiences and/or real behaviour. For these questions, we can describe some particular OA patterns (Table 1).

\begin{tabular}{|c|l|c|c|}
\hline$\#$ & Topic & High & Low \\
\hline 26 & Use of HAL & $\begin{array}{c}\text { Mathematics, Informatics, } \\
\text { Nuclear physics }\end{array}$ & Biology \\
\hline 27 & Deposit records in HAL & Nuclear physics & Biology, Earth Sciences \\
\hline 28 & Deposit documents in HAL & Mathematics, Informatics & Chemistry Biology \\
\hline 29 & Use of other repositories & Mathematics & Chemistry, Biology, Ecology \\
\hline 38 & Payment of APCs & Physics, Biology & Mathematics, SS\&H \\
\hline 39 & Intention to pay APCs & Ecology, Biology & Mathematics, SS\&H \\
\hline 41 & Referencing output in repository & Informatics & Biology \\
\hline 88 & Legal problems with deposit & SS\&H & Mathematics \\
\hline
\end{tabular}

Table 1: Disciplinary differences (the institutes have been replaced by the disciplines, see appendix 2) 
The most salient results can be summarized under three different aspects:

HAL: Contrary to its multidisciplinary vocation and positioning, but just like its initial model, i.e. arXiv, the part of scientists from Nuclear Physics, Informatics and Mathematics using the national repository HAL is significantly higher than the part of scientists from Biology, Chemistry or Earth Sciences and Astronomy. This does not change the multidisciplinary character of HAL's deposits and usage but shifts the focus on the fact that its relative importance differs between the CNRS scientific communities.

APCs: Especially scientists and laboratories in life sciences (Biology) but also in Physics and environmental research (Ecology) have already published articles with APCs and/or intend to do so while scientists from Mathematics and Social Sciences and Humanities are more reluctant than others to publish their articles in this way.

Legal problems: Researchers from the social sciences and humanities report having experienced legal problems more often with the deposit of copyrighted material in an open repository than colleagues from other disciplines, in particular from Mathematics.

\section{Discussion}

\section{Attitude towards open access and behavioural gap}

The survey reveals a globally positive and favourable attitude towards resource sharing and the development and promotion of the national open access infrastructure HAL amongst scientists from the French Research Center. This globally positive attitude towards open access, and in particular with the green road (self-archiving) is consistent among the whole sample, without significant differences between disciplines.

Focussing on the gold road (OA journals), the large scale survey of the Study of Open Access Publishing (SOAP) has shown similar response patterns: "One of the key questions asked in the survey is whether respondents considered open access publishing beneficial for their research field (...). In total $89 \%$ of published researchers answering to the survey thought that journals publishing open access articles were beneficial for their field" (DallmeierTiessen et al. 2011, p.3). Fry et al. (2010) reported that two-thirds of respondents were convinced that there is a role for open repositories in scholarly communication.

This is not self-evident or normal. Based on two surveys, Creaser et al. (2010) regretted that "many researchers" maintained a suspicion of open access publications. Such a global suspicion cannot be detected in the French sample. A more critical stance, and also disciplinary differences, are related not to expressed opinions but to real practice. The CNRS survey shows a gap between generally positive attitudes and less supportive behaviours, i.e. self-archiving and above all APCs. In spite of globally constructive opinions on open access, French scientists are more reluctant when it comes to "acting out" - probably because they discover the "costs" of open access, in terms of APCs and time.

It may be that disciplinary, community traditions of scientific communication impact information behaviours more than attitudes. Or it may also be that the survey itself encouraged a positive bias towards open access. Even so, this "behavioural gap" can be interpreted as a cognitive dissonance and exploited as such when promoting self-archiving and open access publishing. At least, this bias will be helpful to convince scientists to adapt their practice to their expressed opinions and attitudes, closing the gap and reducing the dissonance.

\section{Open access clusters?}

The French survey does not reveal any significant "OA clusters" among the scientists. One particular question was whether an "OA-reluctant group" could be identified. While Creaser et al. (2010) mentioned "many researchers" with suspicion of open access publishing, Fry et al. (2010) identified only a small group of $4 \%$ authors opposed to self-archiving, and $30 \%$ 
respondents without a strong or definite opinion. Regarding mandatory open access, Swan \& Brown (2005) had come to a comparable result: “ (...) the great majority of authors — in the whole population, in each subject area and in each region of the world - have no objection to a mandate to self-archive imposed by their employer or research funder and would willingly comply with it. Most of the rest (13\%) would comply reluctantly. Only a very small percentage (5\%) would not comply at all" (p.66).

In the French sample, the part of reluctant respondents, with consistently non-supportive or negative response patterns is $2 \%$ for opinions and expressed needs and $4 \%$ for reported behaviours. The others, if not clearly favourable and supportive towards open access, are hesitant or undecided. However, two or three aspects need attention: nearly two-thirds are opposed to mandatory self-archiving in HAL (63\%); more than the half do not and will not pay APCs (57\%); and only a small group of scientists express consistently favourable opinions about open access (9\%) and/or show positive interest in open access (14\%).

The opposition to mandatory self-archiving can perhaps be explained by the way some scientists perceive the national repository HAL - because some institutions adopted mandatory policies with obligatory self-archiving in HAL, some scientists do not consider any longer HAL as a tool for direct communication but rather as a tool for scientometrics and evaluation, i.e. as a tool of institutional control which they reject.

Concerning APCs, the survey does not distinguish between full open access journals and hybrid journals. One part of the opposition to APCs may have its reason in the fact that some disciplines are now accustomed to full OA journals and very rapid publishing (in particular life sciences with journals like $B M C$ and $P L o S$ ) while others like Mathematics or Social Sciences and Humanities did not up to now adopt this way of publishing research.

Taken together, this means that a large part of the scientists - 80-85\% - are somewhere "inbetween", with positive experiences and opinions but also with some doubts, suspicions and questions. They represent the real challenge of the future communication and promotion of open access, HAL and OA publishing.

\section{The impact of disciplines}

Fry et al. (2010) described a favourable stance towards open repositories in Social Sciences and Humanities, in Physics and Mathematics while researchers from life sciences (Biology) showed less enthusiasm for self-archiving. A high support for open access in most of the humanities and social sciences (>90\%) and in Chemistry, Astronomy, Physics, Engineering and related disciplines (around 80\%) was also reported by Dallmeier-Thiessen et al. (2010).

Eger et al. (2013) asserted "remarkable differences" between disciplines - a larger share of open access publishing in natural science disciplines, in particular in Biology, and more support for self-archiving in Physics and Mathematics.

The French survey confirms similar disciplinary differences - a stronger support for selfarchiving of records and documents in HAL by scientists from Mathematics, Physics and Informatics than from Biology, Earth Sciences and Chemistry; and more experience and positive feelings with open access publishing and payment of APCs in Biology than in Mathematics or in Social Sciences and Humanities.

Why is this so? Björk et al. (2010) believe that "possible reasons for the differences between disciplines (...) include uneven spread of available OA journals across disciplines, unequal possibilities for financing author charges, availability of well-established subject based repositories in some disciplines (and) traditions of making preprints available in some subjects". Eger et al (2010) mention academic experience (seniority and status) as another potential determinant. All are convinced that because of these factors and differences a "onesize-fits-all" approach is not appropriate.

Especially in Biology, there are very few preprints and the rapid publishing and exchange of research results is organized thru full OA journals like $B M C$ and $P L o S$. Non usage of HAM 
does not necessarily mean rejection. Earth Sciences and Chemistry, on the other side, probably are (still) more attached to traditional journal publishing and "their" preferred publishers like ACS or Springer.

Figure 3 shows the ten CNRS institutes on a map with two variables - the usage of HAL (green road, horizontal axis, \#26) and the payment of APCs (gold road with payment, vertical axis, \#38). The relative size of the ten institutes in the survey sample is represented through the size of the dot.

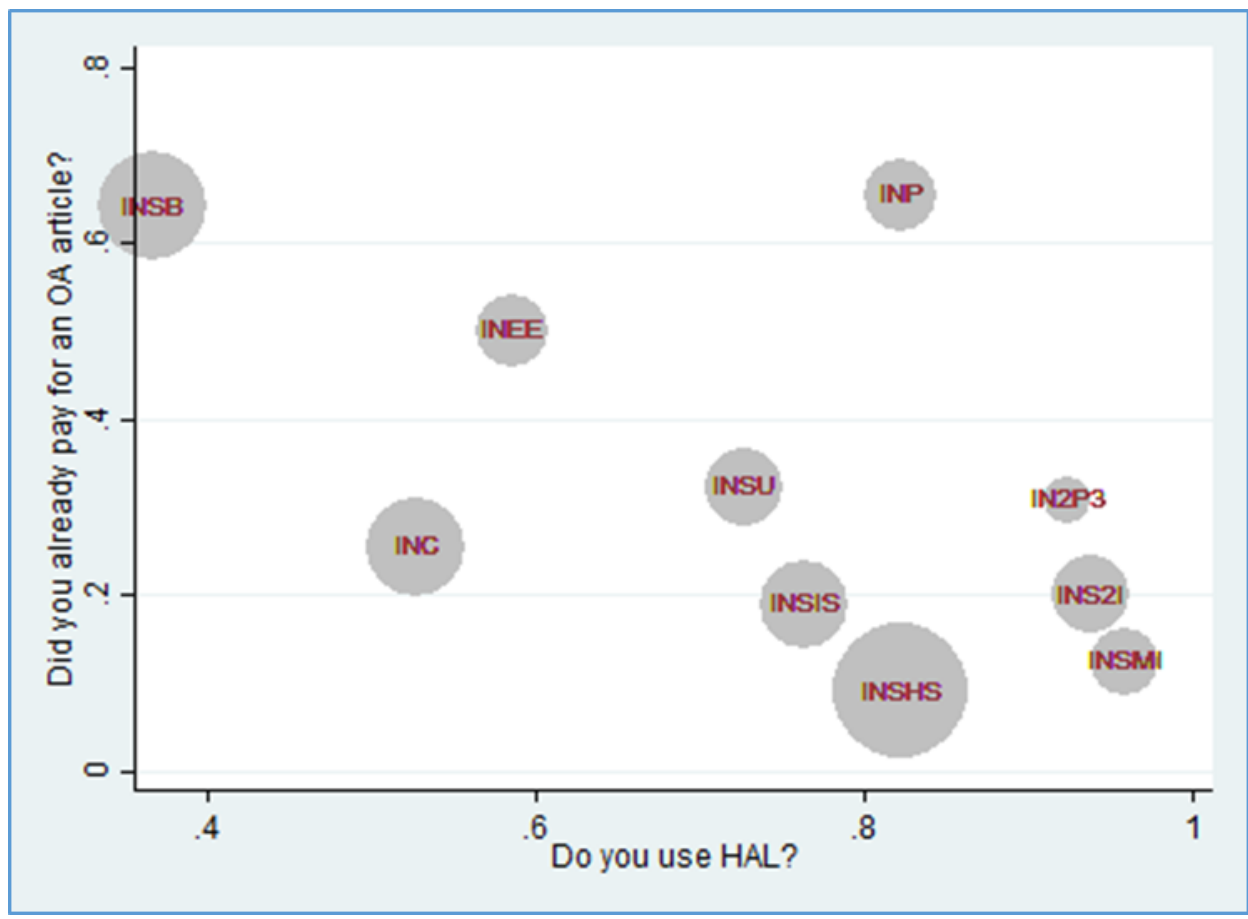

Figure 3: Usage of HAL and payment of APCs by the CNRS institutes $(\mathrm{N}=432)$

The map reveals four "extreme" behavioural patterns:

- Physics (INP): committed to self-archiving and OA publishing with APCs.

- Chemistry (INC): low self-archiving and OA publishing with APCs.

- Biology (INB): committed to OA publishing with APCs but low self-archiving.

- Mathematics (INSMI), Social Sciences and Humanities (INSHS), Informatics (INS2I) and Nuclear Physics (IN2P3): committed to self-archiving but not to OA publishing with APCs.

Scientists from Chemistry, Biology and Physics have in common their opposition to mandatory self-archiving. One explanation may be that they remain strongly committed to "their" international journals of excellence for the dissemination of their works and papers.

Mathematicians are rather untypical in this sample in the way they use HAL (and other repositories), but are not interested in further development. Perhaps the reason is that for 1015 years now the French Mathematics community - an excellence cluster in the landscape of French science, led by the CNRS INSMI - has developed its own digital library and OA tools, in partnership with their traditional publishers and with French and European learned societies.

The position of INEE (Environmental Sciences) somewhere in the middle (barycentre) between Biology, Earth Sciences and Social Sciences and Humanities may find an explanation in the fact that this research institute was recently created with scientists mainly 
from these three disciplines. Thus their position probably does not reflect a disciplinary usage but rather an average of different behaviours.

However, the figures must be interpreted with caution because of the large categories and because of the small numbers in the subsamples, especially in questions with lower response rates.

\section{What about document supply?}

As mentioned above, the CNRS survey was not limited to open access but covered a large scale of information services and needs. Two-thirds of the respondents are satisfied with the digital resources (journals, monographs, databases...) available through the large disciplinary CNRS portals ${ }^{10}$ even if many would like a unique gateway, more inter-disciplinary portals and also more specialised, domain-specific content. They are aware of open access and use all kinds of information freely available on the Internet. Many ask for further development and promotion of open access infrastructures.

However they do not explicitly ask for document supply, and most of them do not rely on the CNRS Refdoc service ${ }^{11}$. For them, document supply obviously remains "in a time warp (...) on the periphery of traditional STM publishing" (Brown 2016, p.207). Will the future development of the French academic inter-lending and document supply change the situation? Bérard et al. (2015) admit that "the development of resources in OA, by the deposit of the researcher or the investments of the publishers in dedicated journals, can only accelerate the end (...) of the 'industrial' supply of article copies" (p.136) and describe a realistic approach to cope with this situation, a "policy of small steps", such as free reciprocal arrangements with some universities or, in the context of the new "CollEx" project ${ }^{12}$, a redesigned and labelled system of document supply with large specialized libraries. The coming years will show the results of this difficult "transition from industrial model to a mediation/identification and retrieval service" (loc.cit.) and its place in Open Science.

\section{Conclusion}

The EU Competitiveness Council has confirmed the strategy of the Amsterdam Call for Action at its meeting on May $27^{\text {th }} 2016$, and adopted conclusions on the transition towards an Open Science system ${ }^{13}$. The outcome document of the Council Meeting highlights that the "Member states agreed to common goals on Open Science and to pursue concerted actions together with the Commission and stakeholders" and that they "committed to open access to scientific publications as the option by default by 2020 and to the best possible re-use of research data as a way to accelerate the transition towards an Open Science system". It says, too, that "Open Science involves moving from a system in which it is difficult to access and locate the results of scientific research to one that openly disseminates results to all kinds of users, such as researchers, knowledge institutions, companies, patient organisations, teachers, students, farmers and citizens in general. It aims at transforming science through ICT tools, networks and media, to make research more open, global, collaborative, creative and closer to society".

The survey with more than 400 CNRS research centres provides an instant photo of the open access attitudes and behaviours of French senior research managers in 2014. In particular the results show that:

1. The CNRS senior research managers (laboratory directors) globally share the positive opinion towards open access revealed by other studies with researchers

\footnotetext{
${ }^{10}$ Source: INIST http://www.inist.fr/?-Portals-\&lang=en

${ }^{11}$ Source: INIST http://www.refdoc.fr/

${ }^{12}$ Source: Ministry of Higher Education and Research http://www.enseignementsuprecherche.gouv.fr/cid99665/collections-d-excellence-pour-la-recherche-\%E2\%80\%93-persee-collex-persee.html ${ }^{13}$ Source: European Council http://www.consilium.europa.eu/en/meetings/compet/2016/05/26-27/
} 
from the UK, Germany, the United States and other countries. However, they are more supportive of open repositories (green road) than of OA journal publishing (gold).

2. The response patterns reveal a gap between generally positive opinions about open access and less supportive behaviours, principally publishing articles with APCs.

3. A small group of senior research managers does not seem to be interested in green or gold open access and reluctant to self-archiving and OA publishing.

4. Similar to other studies, the French survey confirms disciplinary differences, i.e. a stronger support for self-archiving of records and documents in HAL by scientists from Mathematics, Physics and Informatics than from Biology, Earth Sciences and Chemistry; and more experience and positive feelings with open access publishing and payment of APCs in Biology than in Mathematics or in Social Sciences and Humanities.

The French survey uncovers attitudes, needs and behaviours similar to other countries, except for OA publishing with APCs where French scientists appear more reluctant and hesitant than their colleagues from other European countries. One explanation may be the fact that France globally spends less for scientific information than other similar countries; also APCs may appear less affordable. However, these differences should not be over-interpreted. Since 2014, the situation has changed in France as well as in other European countries, and open access to scientific information is fast becoming the dominant model of academic communication.

Today, the debate is no longer on pros and cons of open access. In 2016 the French parliament will probably adopt a new law ("Loi pour une République Numérique") granting secondary exploitation rights to scientists, similar to German, Austrian and Dutch legislation. Together with the other EU Member States, France is committed to Open Science and will continue to increase the availability of French research results. The challenge today is how to get there. For more than 15 years, France has developed an open access infrastructure with national operating agents, a large open repository (HAL) and public OA journal and book platforms especially in social sciences and humanities. This public infrastructure is now in competition with OA publishing and APCs mainly controlled by large corporate publishers.

One challenge is the control over dissemination, access and preservation of research results, and over innovation in the field of academic publishing. Another challenge is the exploitation of the growing volume of research results through content mining, and the control of these technologies and tools. Will the research community maintain (or regain) control over its data, over usage, impact, evaluation etc.? Who will add value to content, who will provide metrics for research output, for networks, experts, emerging topics etc.? Will the dysfunctional scientific information market survive, with its oligopolies, mergers and benefits? Should it?

Open Science is a great and exciting idea, and the European countries are right to set a short-term goal of full open access in 2020. French scientists appear ready and willing to meet the challenge - but not at any cost. The survey points to the fact that one size will not fit all. The development of services to researchers for better sharing of knowledge across a smoother flow of scientific production must respect the specific characteristics of scientific communities. Not only do significant differences persist between scientific disciplines, which exclude and condemns to failure any "easy solution", but significant differences exist also between countries and their specific investments, infrastructures, organisations, research policies and scientific cultures. Seeking to impose the same approach to open access may lead to a dead end or simply elsewhere and definitely not to Open Science. 


\section{Bibliography}

Bérard, R., Fleuret, E., Gillet, J. and Mougel, J.-Y. (2015), “Academia and document supply: unsustainable contradictions at INIST?", Interlending \& Document Supply, Vol.43 No.3, pp.131-137, available at http://dx.doi.org/10.1108/ilds-05-2015-0017

Björk, B.-C., Welling, P., Laakso, M., Majlender, P., Hedlund, T. and Gudnason, G. (2010), "Open access to the scientific journal literature: Situation 2009", PLoS ONE, Vol.5 No.6, e11273+, available at http://dx.doi.org/10.1371/journal.pone.0011273

Brown, D. J. (2016), Access to scientific research. Challenges facing communications in STM, Berlin/Boston, De Gruyter Saur.

Creaser, C. (2010), "Open access to research Outputs-Institutional policies and researchers' views: Results from two complementary surveys", New Review of Academic Librarianship, Vol.16 No.1, pp.4-25, available at http://dx.doi.org/10.1080/13614530903162854

Dallmeier-Tiessen, S., et al. (2011), Highlights from the SOAP project survey. What scientists think about open access publishing. Report, SOAP Project, available at http://arxiv.org/abs/1101.5260

Eger, T., Scheufen, M. and Meierrieks, D. (2013), The determinants of open access publishing: Survey evidence from Germany, available at http://dx.doi.org/10.2139/ssrn.2232675

EUA (2015), EUA's open access checklist for universities: a practical guide on implementation. Report, European University Association, Brussels, available at http://www.eua.be

Fry, J., Oppenheim, C., Probets, S., Creaser, C., Greenwood, H., Spezi, V. and White, S. (2010), PEER behavioural research: Authors and users vis-à-vis journals and repositories. Baseline report. LISU Loughborough University, available at http://www.peerproject.eu/fileadmin/media/reports/Final_revision_behavioural_baseline_report_-_20_01_10.pdf

Mann, F., von Walter, B., Hess, T. and Wigand, R. T. (2009), "Open access publishing in science", Commun. ACM, Vol.52 No.3, pp.135-139, available at http://dx.doiorg/10.1145/1467247.1467279

Morris, S. and Thorn, S. (2009), "Learned society members and open access", Learned Publishing, Vol.22 No.3, pp.221-239, available at http://dx.doi.org/10.1087/2009308

Nariani, R. and Fernandez, L. (2012), "Open access publishing: What authors want", College \& Research Libraries, Vol.73 No.2, pp.182-195, available at http://dx.doi.org/10.5860/crl$\underline{203}$

Ramjoué, C. (2015), "Towards Open Science: The vision of the European Commission", Information Services \& Use, Vol.35 No.3, pp.167-170, available at http://dx.doi.org/10.3233/isu-150777

Swan, A. and Brown, S. (2005), Open access self-archiving: An author study. Report, Key Perspectives Limited, Truro, available at http://cogprints.org/4385/

Ware, M. and Mabe, M. (2015), The STM report: An overview of scientific and scholarly journal publishing. International Association of STM Publishers, Oxford, available at http://www.stm-assoc.org/2015_02_20_STM_Report_2015.pdf

\section{Appendix 1 - The survey questions}

The complete survey (French version) is available online (see footnote 8). This is the list of the fifteen items re-analysed for the purpose of our study:

Experience with open access

\#26 Do you use HAL? 
\#27 If so, do you deposit bibliographic records in HAL?

\#28 If so, do you deposit articles with full text in HAL?

\#29 If not, do you use other repositories than HAL?

\#38 Have you already paid for an article to be available in open access?

\#41 Do you reference the research unit's scientific output (also) through an open repository?

\#88 Have you already had legal problems with the deposit of copyrighted material in an open repository?

\section{Attitudes to open access}

\#25 Are you ready to share your digital resources with scientists from other laboratories?

\#37 Are you in favour of the sharing of open access deposits through a European or international network?

\#39 If not (payment for OA article), do you intend to do so?

\section{Needs and demands}

\#30 Should the HAL services (deposits) be better promoted and known?

\#31 Should the HAL services be developed further on?

\#32 Should HAL distinguish between deposits of preprints and other items (articles)?

\#36 Should the deposit in HAL become mandatory?

\#84 Which kind of service would you need most? The management of open access?

\section{Appendix 2 - The CNRS research institutes}

\begin{tabular}{|l|l|l|}
\hline IN2P3 & $\begin{array}{l}\text { Institut national de physique nucléaire et } \\
\text { de physique des particules }\end{array}$ & Nuclear and particle physics \\
\hline INC & Institut de chimie & Chemistry \\
\hline INEE & Institut écologie et environnement & Ecology and environment \\
\hline INP & Institut de physique & Physics \\
\hline INS2I & $\begin{array}{l}\text { Institut des sciences de l'information de } \\
\text { leurs interactions }\end{array}$ & Informatics \\
\hline INSB & Institut des sciences biologiques & Biology \\
\hline INSHS & Institut des sciences humaines et sociales & Social sciences and humanities \\
\hline INSIS & $\begin{array}{l}\text { Institut des sciences de l'ingénierie et des } \\
\text { systèmes }\end{array}$ & Engineering and systems \\
\hline INSMI & $\begin{array}{l}\text { Institut national des sciences } \\
\text { mathématiques et de leurs interactions }\end{array}$ & Mathematics \\
\hline INSU & Institut national des sciences de l'univers & Earth sciences and astronomy \\
\hline
\end{tabular}

The complete list of the CNRS research laboratories can be consulted at the following address: http://www.cnrs.fr/fr/recherche/labos.htm

All web sites visited in May 2016.

\section{Biographical Details:}


Joachim Schöpfel is senior lecturer, former head of the department of information and document sciences at the University of Lille and researcher at the GERiiCO laboratory. He is also director of the French national reproduction centre for $\mathrm{PhD}$ theses (ANRT). He is interested in scientific information, academic publishing, open access, grey literature, usage statistics and service development. He is member of GreyNet, NDLTD and euroCRIS.

Coline Ferrant is a PhD student in the Dual $\mathrm{PhD}$ program in Sociology between Northwestern University and Sciences Po. At Sciences Po, she is affiliated to the Observatoire Sociologique du Changement laboratory (Sciences Po / CNRS). She is also an associate fellow at the Alimentation et Sciences Sociales laboratory (INRA).

Francis André is acting as a special advisor for research data at the CNRS Scientific Information Department, based in Paris, working on a variety of projects across scientific data management and open science. He trained in geology and computer sciences, with a PhD from University of Nancy. He initiated and co-chairs the Research Data working group of the French scientific digital library initiative (BSN).

Renaud Fabre is head of the CNRS Scientific Information Department at Paris since 2013. He is professor of economics and former president of the University of Paris VIII VincennesSt Denis. He graduated in political sciences and holds a PhD in economics. 